\title{
TINGKAT KEBISINGAN PADA INSTITUSI PERGURUAN TINGGI POLITEKNIK KESEHATAN KEMENKES MAKASSAR TAHUN 2016
}

The Level Of Noise In The Higher Education Institution Of Makassar Kemenkes Health 2016 Hamsir Ahmad ${ }^{1}$, Muhammad Rifai ${ }^{2}$

1,2 Jurusan Kesehatan Lingkungan Poltekkes Kemenkes Makassar

*)mrifai844@gmail.com

\begin{abstract}
Noise is unwanted noise from operations and activities to the level of a certain time and that can cause human health problems and comfort appropriate environmental. Noise South Sulawesi governor according to regulations No. 69 of 2010 PERGUB on the Threshold Limit Value (TLV) Physical Factors in educational environments and criteria of environmental damage that is $55 \mathrm{~dB}$. The purpose of this study, to determine the level of noise in the college Polytechnic Health MoH Makassar. This type of research is observational descriptive approach to obtain factual data and field measurement using a measuring instrument (Sound Level Meter). The results of measurements of noise intensity in the Department of Environmental Health at point 1 on average $57.9 \mathrm{~dB}, 2$ points on average $50.7 \mathrm{~dB}$, and 3 points on average $49.5 \mathrm{~dB}$. Department of Pharmacy at one point an average of $70.4 \mathrm{~dB}$, 2 points on average $60.1 \mathrm{~dB}$, and 3 points on average $54.8 \mathrm{~dB}$. Department of Nursing at point 1 on average $58.4 \mathrm{~dB}, 2$ points on average $50.1 \mathrm{~dB}$, and 3 points on average $51.2 \mathrm{~dB}$. As well as the Department of Nutrition at point 1 on average $61.5 \mathrm{~dB}, 2$ points on average $53.9 \mathrm{~dB}$, and 3 points on average $49.9 \mathrm{~dB}$. Conclusion of the study, that the noise intensity In Higher Education Institution Polytechnic Health Department MoH Makassar three (environmental health, nursing, and nutrition) are eligible and the majors (pharmaceuticals) do not qualify for noise beyond the NAB by the governor of South Sulawesi regulations Number: PERGUB.no 69 2010. type noisy in Makassar MoH Health Polytechnic was noisy disjointed.

Therefore, to minimize the noise can be done by arrangement of building classrooms, additional living fences and efforts to plant trees near the fence.
\end{abstract}

Key Words $\quad$ : Noise, Health Polytechnic Makassar,NAB.

\section{ABSTRAK}

Kebisingan adalah bunyi yang tidak diinginkan dari usaha atau kegiatan dalam tingkat dan waktu tertentu yang dapat menimbulkan gangguan kesehatan manusia dan kenyamanan lingkungan.Kebisingan yang sesuai peraturan gubernur sulawesi selatan Nomor : PERGUB.no 69 tahun 2010Tentang Nilai Ambang Batas (NAB) Faktor Fisik di lingkungan pendidikan dan Kriteria kerusakan lingkungan hidup yaitu 55 dB.Tujuan penelitian ini,Untuk mengetahui tingkat kebisingan di perguruan tinggi Politeknik Kesehatan Kemenkes Makassar. Jenis penelitian ini yaitu observasional dengan pendekatan deskriptif untuk memperoleh data faktualdanpengukuran di lapangandenganmenggunakanalatukur (Sound Level Meter).Hasil pengukuran intensitas kebisingan di Jurusan Kesehatan Lingkungan pada titik 1 rata-rata $57,9 \mathrm{~dB}$, titik 2 rata-rata 50,7 dB, dan titik 3 rata-rata 49,5 dB. Jurusan Farmasi pada titik 1 rata-rata $70,4 \mathrm{~dB}$, titik 2 rata-rata $60,1 \mathrm{~dB}$, dan titik 3 rata-rata 54,8 dB. Jurusan Keperawatan pada titik 1 rata-rata 58,4 dB, titik 2 rata-rata 50,1 dB, dan titik 3 rata-rata 51,2 dB. Serta Jurusan Gizi pada titik 1 rata-rata $61,5 \mathrm{~dB}$, titik 2 rata-rata 53,9 dB, dan titik 3 rata-rata 49,9 dB. Kesimpulanpenelitian, bahwa Intensitas kebisingan Pada Institusi Perguruan Tinggi Politeknik Kesehatan Kemenkes Makassar tiga Jurusan (kesling, keperawatan, dan Gizi) memenuhi syarat dan satu jurusan (farmasi) tidak memenuhi syarat karena kebisingannya melampaui NAB menurut peraturan gubernur sulawesi selatan Nomor : PERGUB.no 69 tahun 2010. Jenis bising yang ada di Politeknik Kesehatan Kemenkes Makassar adalah bising terputus-putus. Oleh karena itu, upaya meminimalisir kebisingan dapat dilakukan dengan cara penataan gedung ruang belajar, penambahan pagar hidup dan upaya untuk menanam pohon di dekat pagar.

Kata Kunci : Kebisingan, Politeknik Kesehatan Kemenkes Makassar,NAB.

\section{PENDAHULUAN}

Kemajuan ilmu pengetahuan dan teknologi telah membawa industry dan mekanisme tumbuh berkembang dalam rangka mewujudkan masyarakat industri yang maju dan mandiri. Berbagai mesin dan peralatan canggih dipergunakan dan diproduksi oleh industri-industri dan perusahaan-perusahaan. Mesin-mesin dan peralatan tersebut disatu sisi sangat penting bagi pembangunan namun juga ternyata membawa dampak negative bagi pembangunan dan kesehatan manusia khususnya tenaga kerja (Atin, 2012).
Pembangunan perguruan tinggi negeri di Perkotaan semakin tahun semakin meningkat sejalan dengan pertumbuhan jumlah penduduk, hal ini membuat kecenderungan yang terjadi di masyarakat yang mengingikan pembangunan perumahan yang dekat dengan perguruan tinggi, terutama dekat dengan jalan raya yang bisa dilalui oleh mobil. Mobil dan motor bukan lagi menjadi barang yang mewah bagi masyarakat, peningkatan jumlah kendaraan bisa dirasakan di jalan-jalan raya yang dekat dengan perguruan tinggi membuat macet, suara bising dan sebagainya. 
Buchari (2007) dalam penelitiannya, menggolongkan gangguan kebisingan dalam dua kategori, yaitu berupa gangguan auditory misalnya gangguan terhadap pendengaran, dan juga berupa non auditory seperti pada gangguan saat komunikasi dan menurunnya semangat kerja, akibat kelelahan dan stress.

Umiati (2011) dalam penelitiannya, menyatakan bahwa kebisingan lalu lintas yang tinggi dalam waktu yang cukup lama akan menimbulkan ketidaknyamanan dan membuat lingkungan sekitar menjadi terganggu.

Keramaian kota Makassar yang mobilitas masyarakat yang semakin meningkat memberikan dampak kebisingan di ruas-ruas jalan yang ada di Kota Makassar yang berada dilnstitusi perguruan tinggi Politeknik Kesehetan Kemenkes Makassar yang terdiri 8 jurusan dan pada dasarnya terbagi menjadi 4 lokasi yang berbeda-beda yang potensial menimbulkan kebisingan sehingga patut diteliti karena berada di dekat jalan raya. Salah satunya seperti Jurusan Kesehatan Lingkungan yang berada di daerah Banta-Bantaeng yang dulunya lokasi dekat kampus adalah kondisi rawa-rawa menjadi lokasi perumahan yang ramai, Jurusan Farmasi yang berada di Jln. Baji Gau yang dulunya hanya jalan kecil seiring berjalanya waktu dan kemajuan ilmu pengetahuan membuat lokasi tersebut menjadi jalan raya yang banyak dilalui kendaraan baik motor maupun mobil, Jurusan Gizi dulunya adalah kampus yang berada pada daerah persawahan sekarang menjadi daerah perkampungan padat penduduk, banyak pembangunan perumahan dan toko-toko yang berdempetan serta Jurusan yang berada di Jln. Bendungan Bili-Bili dan menjadi pusat semua jurusan yaitu keperawatan daerahnya adalah kebun sekarang menjadi pusat pembangunan pendidikan. Maka dari itu terjadinya pergeseran waktu yang membuat lokasi kampus menjadi dekat dengan intensitas kebisingan yang berbeda-beda sesuai aktifitas manusia yang ada di lingkungan lokasi kampus politeknik kesehatan kemenkes makassar tersebut.

Berdasarkan hasil pengukuran mahasiswa Kesehatan Lingkungan D.IV Angkatan 2013 intensitas kebisingan di ruang Laboratorium Penyehatan Air Jurusan Kesehatan Lingkungan Poltekkes Kemenkes Makassar di dapatkan intentitas kebisingan $78,76 \mathrm{~dB}$ dimana melebihi Nilai Ambang Batas.
Sesuai dengan Peraturan Gubernur Sulawesi Selatan 69 thn 2010 Baku Mutu Dan Kriteria Kerusakan Lingkungan Hidup, disebutkan bahwa untuk kegiatan sekolah dan sejenisnya, tingkat kebisingan tidak di perbolehkan melebihi $55 \mathrm{~dB}$.

Jika dilihat dari kondisi lingkungan Institusi Perguruan Tinggi Politeknik Kesehatan Makassar yang terdiri 8 jurusan yang terletak di pusat keramaian kota Makassar, yang letak lokasi jurusan yang berbeda-beda: 2 Jurusan berada di BantaBantaeng (Kesehatan Lingkungan dan Analis), 1 Jurusan berada di Jln. Baji Gau (Farmasi), 2 Jurusan berada di Daya Kel. Paccerakkan (Fisioterapi dan Gizi) dan 3 Jurusan berada di Tidung Jln. Bendungan BiliBili (Keperawatan, Keperawatan Gigi, dan Bidan) maka perlu dilakukan penelitian di beberapa jurusan yang berdekatan dengan sumber kebisingannya berada dekat dengan perumahan dan jalan raya, karena sebelum berdirinya kampus dilakukan analisis mengenai dampak lingkungan sehingga berjalannya waktu kondisi lingkungan Politeknik Kesehatan Kemenkes Makassar akan berubah. Dan dari itu apakah tingkat kebisingan masih memenuhi syarat untuk lingkungan pendidikan sehingga penelitian ini dapat diketahui tingkat kebisingan di Institusi Politeknik Kesehatan Kemenkes Makassar.

Berdasarkan latar belakang tersebut di atas, maka penulis tertarik untuk melakukan penelitian yang memungkinkan intensitas kebisingan berubah seiring berjalannya waktu dan kondisi lingkungan yang berubah Pada Institusi Perguruan Tinggi Politeknik Kesehatan Makassar. Maka dari itu di lakukan penelitian mengenai "Studi Tingkat Kebisingan Pada Institusi Perguruan Tinggi Politeknik Kesehatan Kemenkes Makassar Tahun 2016."

\section{METODE \\ Jenis Penelitian}

Penelitian ini merupakan penelitian deskriptif untuk memperoleh gambaran secara factual dan pengukuran di lapangan dengan menggunakan alat ukur ( Sound Level Meter).

\section{Gambaran umum}

\section{a. Lokasi Penelitian}

Penelitian ini berlokasi di Perguruan Tinggi Politeknik Kesehatan Makassar yang terbagi di empat lokasi berbeda yaitu Jln Banta-Bantaeng 
(Jurusan Kesehatan Lingkungan), Jln. Baji Gau (Jurusan Farmasi), Jln. Bendungan Bili-Bili (Jurusan Keperawatan), dan Jln Paccerakkang (Jurusan Gizi).

\section{b. Waktu Penelitian}

tahap, yaitu :

Waktu penelitian dibagi menjadi 2

1. Tahap persiapan, untuk kepentingan proposal berlangsung pada Desember 2015.

2. Tahap kedua yaitu pelaksanaan kegiatan penelitian yang berlangsung pada hari sabtu saat libur dengan alasan ingin tau persis berapa kondisi kebisingan sesungguhnya tanpa ada latar belakang kebisingan. Waktu pengukuran dilaksanakan :
a. Waktu pagi hari $06.00-12.00$ WITA dengan 3 titik pengukuran
b. Waktu siang hari $12.00-18.00$ WITA dengan 3 titik pengukuran.
c. Waktu malam hari $18.00-23.00$ WITA dengan 3 titik pengukuran.

Dalam satu jurusan dilakukan 9 kali pengukuran dalam sehari.

\section{Variabel Penelitian}

1. Variabel bebas yaitu Institusi Politeknik Kesehatan Kemenkes Makassar

2. Variabel terikat yaitu Kebisingan

3. Variabel pengganggu yaitu angin, jalur lalu lintas, fasilitas dan sarana kampus.

\section{Definisi operasional}

1. Institusi Politeknik Kesehatan Kemenkes Makassar yang dimaksud adalah perguruan tinggi kesehatan yang terdiri delapan Jurusan yaitu Jurusan Kesehatan Lingkungan, Analis, Farmasi, Kebidanan, Keperawatan, Keperawatan Gigi, Fisioterapi dan Gizi.

2. Tingkat kebisingan yang dimaksud adalah nilai/angka yang diperoleh dari hasil pengukuran dengan menggunakan alat yaitu Sound Level Meter dan dinyatakan dengan desibel(dB).

Zona B (Kebisingan antara $45 \mathrm{~dB}$ sampai $55 \mathrm{~dB}$ di dalam dan diluar ruangan). Zona yang diperuntukkan bagi perumahan, tempat pendidikan, rekreasi dan sejenisnya.

3. Kecepatan angin yang di maksud adalah kecapatan udara yang bergerak yang mempengaruhi tingkat kebisingan sehingga dapat mengganggu intensitas kebisingan.

4. Jalur Lalu Lintas yang di maksud adalah jalur kendaraan yang diduga menjadi sumber bising dari suara yang di hasilkan.

5. Fasilitas dan sarana kampus yang dimaksud adalah fasiltas atau peralatan kampus seperti laboratorium dan tempat parkir kampus.

\section{Kriteria Obyektif}

1. Dikatakan memenuhi syarat :Apabila tidak melampaui Nilai Ambang Batas (NAB) yaitu55 dB (PeraturanGubernur Sulawesi Selatan 69 Thn 2010 Tentang Baku Mutu Dan Kriteria Kerusakan Lingkungan Hidup).

2. Dikatakan tidak memenuhi syarat :Apabila melampaui Nilai Ambang Batas yaitu55 dB (Peraturan Gubernur Sulawesi Selatan 69 Thn 2010 Tentang Baku Mutu Dan Kriteria Kerusakan Lingkungan Hidup).

\section{Populasi Dan Sampel}

1. Populasi

Populasi dalam penelitian ini adalah semua Institusi Perguruan Tinggi Politeknik Kesehatan Kemenkes Makassar.

\section{Sampel}

Cara penentuan sampel dilakukan dengan metode purposive sampling (sampel yang sengaja diambil peneliti) dengan jumlah sampel sebanyak 4 jurusan dengan pertimbangan $/$ kriteria.

HASIL

Pengukuran intensitas kebisingan yang dilaksanakan Pada Institusi Perguruan Tinggi Politeknik Kesehatan Kemenkes Makassar yang terdiri dari Jurusan Kesehatan Lingkungan, Jurusan Farmasi, Jurusan Keperawatan, dan Jurusan Gizi. Melakukan pengukuran kebisingan dengan menggunakan Sound Level kemudian diolah dan disajikan dalam tabel dan dibandingkan apakah memenuhi syarat NAB di lingkungan fisik pendidikan pergub sulsel69 thn 2010 Baku Dan Kriteria Kerusakan lingkungan Hidup yaitu $55 \mathrm{~dB}$ 
Tabel 1

Intensitas Kebisingan Pada Politeknik Kesehatan Kemenkes Makassar

\begin{tabular}{|c|l|l|l|l|l|}
\hline \multirow{2}{*}{ No } & \multirow{2}{*}{ Jurusan } & \multicolumn{3}{|c|}{ Titik } & \multirow{2}{*}{ Keterangan } \\
\cline { 3 - 5 } & & $1(\mathrm{~dB})$ & $2(\mathrm{~dB})$ & $3(\mathrm{~dB})$ & \\
\hline & & & & & \\
\hline & $\begin{array}{l}\text { Kesehatan } \\
\text { Lingkungan }\end{array}$ & 57,9 & 50,7 & 49,5 & $\begin{array}{l}\text { 3 Jurusan } \\
\text { tidak } \\
\text { melampau } \\
\text { ibatas NAB } \\
\text { dan 1 } \\
\text { Jurusan } \\
\text { melampaui } \\
\text { NAB }\end{array}$ \\
\cline { 3 - 5 } & & & & & \\
\hline 3 & Keperawatan & 58,4 & 50,1 & 51,2 & \\
\hline 4 & Gizi & 61,5 & 53,9 & 49,9 & \\
\hline
\end{tabular}

\section{PEMBAHASAN}

1. Intensitas Kebisingan Pada Jurusan Kesehatan Lingkungan

Kebisingan pada lingkungan pendidikan di Politeknik Kesehatan Kemenkes Makassar dapat bersumber dari suara kendaraan bermotor dan sebagainya, jenis kebisingan yang ada di jurusan kesehatan lingkungan yaitu Kebisingan terputus-putus, dimana kebisingan yang berlangsung tidak terus menerus, misalnya kebisingan yang terdapat jalan raya yang sumber bisingnya pada kendaraan bermotor.

Pengukuran intensitas kebisingan dilakukan pada hari libur sehingga dapat diketahui seberapa besar kebisingan yang ada di Jurusan Kesehatan Lingkungan tanpa adanya latar belakang suara yang timbulkan di lokasi tersebut misalnya keberadaan mahasiswa dan dosen yang melakukan proses belajar mengajar tidakakan diketahui kebisingan sesungguhnya dari lokasi kampus Kesehatan Lingkungan.

Berdasarkan hasil pengukuran mahasiswa (i) Kesehatan Lingkungan D.IV Angkatan 2013 intensitas kebisingan di ruang Laboratorium Penyehatan Air Jurusan Kesehatan Lingkungan Poltekkes Kemenkes Makassar mendapatkan hasil pengukuran yaitu sebesar 78,76 dBa dimana melebihi Nilai Ambang Batas.

Dari hasil pengukuran intensitas kebisingan di Jurusan Kesehatan Lingkungan yang dilakukan pada pagi, siang, dan malam hari didapat rata-rata di titik $1(57,9 \mathrm{~dB})$ titik $2(50,7 \mathrm{~dB})$ dantitik 3 $(49,5 \mathrm{~dB})$ menunjuk kan bahwa pada titik 1 tidak memenuhi syarat disebabkan sumber bising dekat dengan titik tersebut yaitu adanya jalan yang dilalui oleh masyarakat yang berada di Jln.Bantabantaeng. Permasalahan yang ada di titik 1 yaitu berada di sumber bising dimana suara yang dihasilkan berada di suara kendaraan motor dan adanya penghubung jalur suara (jalur kendaraan) sehingga suara dapat sampai ke dalam kampus. Namun karena pada titik 1 tidak memenuhi syarat disebabkan jarak dari jalan yang dilalui kendaraan dengan lokasi belajar mengajar yang jauh dari sumber bising maka pada titik ke 2 diambil sebagai acuan standar kebisingan dikawasan pendidikan. Gangguan kebisingan yang akan timbul pada titik 1 yang tidak memenuhi syarat yaitu akan mengganggu kosentarasi belajar pada saat proses belajar mengajar dilaksanakan pada pagi hari karna letak gedung dekat dengan jalan yang dilalui kendaran bermotor dan hasil pengukuran menunjukkan bahwa jurusan kesehatan lingkungan memenuhi syarat NAB faktorfisik di lingkungan pendidikan sesuai dengan Pergub Sulsel 69 thn 2010 Baku Mutu Dan Kriteria Kerusakan Lingkungan Hidup yaitu sebesar (55 dB).

Upaya yang harus dilakukan pada Jurusan Kesehatan Lingkungan di titik yang intensitas kebisingan melampaui nilai ambang batas (NAB) yaitu penanaman pohon untuk meminimalisir kebisingan di dekat pagar dan adanya upaya pengendalian bising mulai dari sumber tempat dimana suara dihasilkan, penghubung jalur suara atau jalur jalan kendaraan.

2. Intensitas Kebisingan Pada Jurusan Farmasi

Kebisingan pada lingkungan pendidikan di Politeknik Kesehatan Kemenkes Makassar dapat bersumber dari suara kendaraan bermotor, suara mesin-mesin industri (bengkel motor) dan sebagainya, jenis kebisingan yang ada di jurusan Farmasi yaitu Kebisingan terputus-putus, dimana kebisingan yang berlangsung tidak terus menerus, misalnya kebisingan yang terdapat jalan 
raya yang sumber bisingnya pada kendaraan bermotor. Pengukuran dilakukan pada hari libur pada saat tidak ada kegiatan di lokasi pengukuran

Hasil pengukuran intensitas kebisingan di Jurusan Farmasi yang dilakukan pada pagi, siang, dan malam hari didapatkan rata-rata di titik $1(70,4$ $\mathrm{dB})$ titik $2(60,1 \mathrm{~dB})$ dantitik $3(54,8 \mathrm{~dB})$ menunjukkan bahwa pada titik 1 dan 2 tidak memenuhi syarat. Menunjukkan bahwa pada titik 1 tidak memenuhi syarat disebabkan sumber bising dekat dengan titik tersebut yaitu adanya jalan yang dilalui oleh masyarakat yang berada di Jln.Banta-cbantaeg. Permasalahan yang ada di titik 1 dan titik 2 yaitu berada di sumber bising dimana suara yang dihasilkan berada di suara kendaraan motor dan adanya penghubung jalur suara (jalur kendaraan) sehingga suara dapat sampai ke dalam kampus.

Hal ini disebabkan lokasi Jurusan Farmasi berada dekat pada jalan raya sehingga aktifitas manusia dekat dengan lokasi sumber bising dan adanya bengkel motor dan warung akibatnya banyak kendaraan yang lalu lalang di lokasi jurusan farmasi di titik 1 sehingga didapatkan hasil intensitas kebisingan yang tertinggi sebesar $(70,4 \mathrm{~dB})$ terjadi karena lokasi kampus yang berada di daerah sumber bising aktifitas manusia yang ramai, jalan raya, dan berdempetan dengan bangunan perumahan serta lokasi kampus yang sempit.

Berdasarkan wawancara yang telah dilakukan salah satu mahasiswa farmasi gangguan kebisingan yang akan timbul pada titik 1 dan 2 yang tidak memenuhi syarat yaitu akan mengganggu kosentarasi belajar mahasiswa yang letak gedung dekat dengan jalan yang dilalui kendaran bermotor.

Dan hasil pengukuran menunjukkan bahwa jurusan farmasi tidak memenuhi syarat NAB factor fisik di lingkungan pendidikan sesuai dengan PergubSulsel 69 thn 2010 Baku Mutu Dan Kriteria Kerusakan Lingkungan Hidup yaitu sebesar ( $55 \mathrm{~dB})$.

Upaya yang harus dilakukan pada Jurusan Farmasi yang intensitas kebisingan tidak memenuhi syarat sebagai lokasi pendidikan yaitu dengan cara penataan gedung ruang belajar penambahan pagar beton atau pagar hidup serta penanaman pohon untuk meminimalisir kebisingan di dekat pagar.

\section{Intensitas Kebisingan Pada Jurusan Keperawatan}

Kebisingan pada lingkungan pendidikan di Politeknik Kesehatan Kemenkes Makassar dapat bersumber dari suara kendaraan bermotor dan sebagainya, jenis kebisingan yang ada di jurusan keperawatan yaitu Kebisingan terputus-putus, dimana kebisingan yang berlangsung tidak terus menerus, misalnya kebisingan yang terdapat jalan raya yang sumber bisingnya pada kendaraan bermotor.

Dari hasil pengukuran intensitas kebisingan di Jurusan Keperawatan yang dilakukan pada pagi, siang, dan malam hari didapatkan rata-rata di titik $1(58,4$ $\mathrm{dB})$ titik $2(50,1 \mathrm{~dB})$ dantitik $3(51,2 \mathrm{~dB})$ menunjukkan bahwa pada titik 1 tidak memenuhisyarat sedangkan 2 dan 3 memenuhi syarat. Ini di sebabkan pada titik 1 dekat dengan aktifitas manusia, jalan yang dilalui oleh warga yang tinggal di perumahan dekat lokasi kampus yang menghubungkan jalan poros ke jalan raya.

Hal ini di sebabkan lokasi Jurusan Keperawatan berada dekat pada jalan, depan dekat jalan titik 1 dan belakang juga dekat jalan titik 3 sehingga pada titik 1 dan 3 hampir sama intensitas kebisingannya walaupun dilakukan pada hari libur aktifitas manusia terjadi dilokasi tersebut sama-sama tinggi yang dekat perumahan sehingga dari ketiga titik tersebut didapat hasil intensitas paling tinggi yaitu sebesar $(58,4 \mathrm{~dB})$.

Gangguan kebisingan yang akan timbul pada titik 1 yang tidak memenuhi syarat yaitu akan mengganggu kosentarasi belajar mahasiswa apabila letak gedung dekat dengan jalan yang dilalui kendaran bermotor. Oleh karena pada titik 2 diambil acuan standar pengukuran kebisingan maka kampus keperawatan memenuhi syarat NAB faktorfisik di lingkungan pendidikan sesuai dengan Pergub Sulsel 69 thn 2010 Baku Mutu Dan Kriteria Kerusakan Lingkungan Hidup yaitu sebesar (55 dB).

Upaya yang harus dilakukan pada Jurusan Keperawatan di titik yang intensitas kebisingan melampaui nilai ambang batas (NAB) yaitu penanaman 
pohon untuk meminimalisir kebisingan di dekat pagar dan adanya upaya pengendalian bising mulai dari sumber tempat dimana suara dihasilkan, penghubung jalur suara atau jalur jalan kendaraan.

\section{Intensitas Kebisingan Pada Jurusan Gizi}

Kebisingan pada lingkungan pendidikan di Politeknik Kesehatan Kemenkes Makassar dapat bersumber dari suara kendaraan bermotor dan sebagainya, jenis kebisingan yang ada di jurusan gizi yaitu Kebisingan terputusputus, dimana kebisingan yang berlangsung tidak terus menerus, misalnya kebisingan yang terdapat jalan raya yang sumber bisingnya pada kendaraan bermotor.

Pengukuran intensitas kebisingan dilakukan pada hari libur sehingga dapat diketahui seberapa besar kebisingan yang ada di Jurusan Kesehatan Lingkungan tanpa adanya latar belakang suara yang timbulkan dilokasi tersebut misalnya keberadaan mahasiswa dan dosen yang melakukan proses belajar mengajar tidakakan diketahui kebisingan sesungguhnya dari lokasi kampus Kesehatan Lingkungan.

Dari hasil pengukuran intensitas kebisingan di Jurusan Gizi yang dilakukan pada pagi, siang, dan malam hari rata-rata di titik $1(61,5 \mathrm{~dB})$ titik 2 $\left.\begin{array}{llll}(53,9 & \mathrm{dB}\end{array}\right)$ dantitik $3 \quad(49,9 \mathrm{~dB})$ menunjukkan bahwa pada titik 1 tidak memenuhi syarat sedangkan titik 2 dan 3 memenuhisyarat. Permasalahan yang ada di titik 1 yaitu berada di sumber bising dimana suara yang dihasilkan berada di suara kendaraan motor dan adanya penghubung jalur suara (jalur kendaraan) sehingga suara dapat sampai ke dalam kampus disebabkan jarak dari jalan yang dilalui kendaraan dengan lokasi belajar mengajar yang jauh dari sumber bising dan juga luas atau lokasi kampus yang memanjang kebelakang sehingga pada titik ke 2 diambil sebagai acuan standar kebisingan dikawasan pendidikan.

Gangguan kebisingan yang akan timbul pada titik 1 yang tidak memenuhi syarat yaitu akan mengganggu kosentarasi belajar mahasiswa apabila letak gedung dekat dengan jalan yang dilalui kendaran bermotorDan hasil pengukuran menunjukkan bahwa jurusan gizi memenuhi syarat NAB faktorfisik di lingkungan pendidikan sesuai dengan PergubSulsel 69 thn 2010 Baku Mutu Dan Kriteria Kerusakan Lingkungan Hidup yaitu sebesar (55 dB).

Upaya yang harus dilakukan pada Jurusan Gizi di titik yang intensitas kebisingan melampaui nilai ambang batas (NAB) yaitu penanaman pohon untuk meminimalisir kebisingan di dekat pagar dan adanya upaya pengendalian bising mulai dari sumber tempat dimana suara dihasilkan, penghubung jalur suara atau jalur jalan kendaraan.

\section{Intensitas Kebisingan Pada Politeknik Kesehatan Kemenkes Makassar} Kebisingan pada lingkungan pendidikan di Politeknik Kesehatan Kemenkes Makassar bersumber dari suara kendaraan bermotor, suara mesinmesin industri dan sebagainya, sehingga dari keempat lokasi jurusan yang ada Politeknik Kesehatan Kemenkes Makassar 1 jurusan tidak memenuhi syarat yaitu Jurusan Farmasi.

\section{KESIMPULAN}

Berdasarkan hasil penelitian yang telah dilakukan, penulis dapat menarik kesimpulan sebagai berikut :

a. Tingkat kebisingan di Jurusan Kesehatan Lingkungan masih di bawah nilai ambang batas.

b. Tingkat kebisingan di Jurusan Farmasi Makassar melampaui nilai ambang batas.

c. Tingkat kebisingan di Jurusan Keperawatan Makassar masih dibawah nilai ambang batas.

d. Tingkat kebisingan di Jurusan Gizi Makassar masih dibawah nilai ambang batas.

\section{SARAN}

Berdasarkan hasil penelitian, maka penulis menyarankan hal-hal sebagai berikut:

a. Kepada pihak Institusi terkait di Politeknik Kesehatan Kemenkes Makassar agar melakukan monitoring intensitas kebisingan di semua Jurusan mulai dari sumber bising atau tempat dimana suara dihasilkan, penghubung atau jalur suara sampai ke penerima (telinga). 
b. Diharapkan pada pihak Jurusan terkait perlunya dilakukan penanaman pohonpohon di dalam dan di bagian pagar kampus seperti pohon bambu jepang, jati emas dan tanaman sirih belanda agar menghambat suara bising yang dihasilkan dari suara kendaraan mobil maupun motor serta cara penataan gedung ruang belajar penambahan pagar beton atau pagar hidup.

c. Agar sumber bising yang dihasilkan oleh aktifitas manusia seperti suara kendaraan bisa terminimalisir perlu adanya penataan ruang belajar di jurusan terkait.

\section{DAFTAR PUSTAKA}

Abdul Rachman, dkk.1990.Bidang Studi Higiene Perusahaan Dan Kesehatan Kerja Pada Institusi Pendidikan Tenaga Sanitasi.Jakarta:Departemen Kesehatan.

Anizar,2009.teknik keselamatan dan kesehatan kerja di industri.Yogyakarta:Graha ilmu.

Anza Hana Wafiroh,2013. Pengukuran Tingkat Kebisingan di Lingkungan SMPN 2 Jember.Jember:Universitas Jember Jurusan Fisika (2013) diakses 6 Januari 2016.

Anonim, 2015 pengertian dan cara menggunakan saound level meter. (http:// alatukur.web.id) diakses 12 Januari 2016

Anonim,2009.Pengertian Kebisingan Kan Kesehatan Kerja.(http://academia.wordpress.com).Diakses 6 Januari 2016.

Atin,2012.Masalah Kebisingan.(http://Atin-Kuliahku.blogspot.com) Diakses 6 Januari 2016.

Evelyn C. Pearce,2009. Anatomi dan Fisiologi Untuk Paramedis.Jakarta:PT.Gramedia.

FitrianiSudarni,2015.Gambaran Kebisingan Dan Kondisi Pendengaran Karyawan Bagian Factory 1 Unit Cutting Saw Pt.Maruki International Indonesia.Makassar: Poltekkes Makassar Jurusan Kesehatan Lingkungan(KTI Tidak Diterbitkan).

Peraturan Menteri Kesehatan RI nomor 718/MENKES/PER/XI/1987 Tentang Pembagian Tingkat Kebisingan Menurut Empat Zona.

Peraturan Gubernur Sulawesi Selatan No.69 Tahun 2010 Tentang Baku Mutu Dan Kriteria Kerusakan Lingkungan Hidup

Ricki M. Mulia,2005. Kesehatan Lingkungan.Yogyakarta:Graha IImu. 